\title{
Does the Configuration of the Street Network Influence Where Outdoor Serious Violence Takes Place? Using Space Syntax to Test Crime Pattern Theory
}

\author{
Lucia Summers $^{1} \cdot$ Shane D. Johnson ${ }^{2}$
}

Published online: 17 June 2016

(C) The Author(s) 2016. This article is published with open access at Springerlink.com

\begin{abstract}
Objectives To examine the effect of the physical layout of the street network on the spatial distribution of outdoor serious violence. Crime pattern theory predicts crime would be more prevalent on more connected, accessible or traveled street segments, as these will be more likely to fall within an offender's awareness space.

Methods The distribution of incidents of outdoor murder, attempted murder and other near-lethal violent crimes that occurred in one London (UK) borough ( $\mathrm{N}=447$ offenses) was analyzed. The space syntax methodology was used to estimate the to- and throughmovement potential of individual street segments.

Results Regression analyses showed higher levels of integration (a measure of tomovement potential) and choice (through-movement potential) were associated with greater odds of a street segment containing at least one crime. Risk was also higher for segments located near to segments with the highest global choice values. In contrast, connectivity (the number of other segments a street segment is adjacent to) was negatively associated with crime occurrence.

Conclusions As predicted, the configuration of the street network was associated with the spatial distribution of outdoor serious violence. Crime reduction measures should be targeted at high-choice street segments (typically main arteries) and segments nearby.
\end{abstract}

Keywords Street networks - Crime pattern theory - Offender awareness spaces . Violence $\cdot$ Space syntax

Shane D. Johnson

shane.johnson@ucl.ac.uk

Lucia Summers

1summers@txstate.edu

1 School of Criminal Justice, Texas State University, 601 University Drive, San Marcos, TX 78666, USA

2 Department of Security and Crime Science, University College London, London WC1H 9EZ, UK 


\section{Introduction}

Research suggests an association between the physical configuration of the street network and the spatial distribution of crime. Typically, more (less) accessible streets, for which urban movement and public awareness of them will be highest (lowest), are found to experience more (less) crime (e.g., Bevis and Nutter 1977). However, previous studies concerned with how the configuration of the street network influences crime pattern formation have mainly focused on property crime (particularly residential burglary), largely neglecting the study of violent crime, which limits the generalizability of the findings. Prior research has also varied in terms of methodological sophistication, often using simple indices of accessibility (Bevis and Nutter 1977) or using solely descriptive statistics or correlation analyses to test theory (Alford 1996; Hillier and Shu 2000), which limits statistical conclusion validity. The influence of other important characteristics of the urban environment, such as variation in land uses that feature in most people's routine activities, have also been ignored in most studies of this kind. Since routine activity nodes affect urban flows and the places with which people will become familiar, their exclusion in previous studies raises the possibility that criminogenic effects attributed to the street network might be spurious.

The current research extends the existing literature in three ways. First, we estimate the association between characteristics of the street network-measured using space syntax, a systematic methodology developed in the field of urban studies-and crime, whilst simultaneously considering the influence of other features of the urban environment. Second, unlike many previous studies, we employ an appropriate statistical framework to test hypotheses, and to estimate the influence of unobserved factors. And, third, we do so for a type of crime rarely studied within this context: outdoor serious violence (OSV). This type of offending refers to violent offenses where the victim(s) sustained lethal or nearlethal injuries (to include murders, attempted murders, as well as serious robberies, sexual attacks, and aggravated assaults) that took place in an open, public space. Such crimes are often the result of an expressive act and consequently it is possible that the configuration of the urban environment will have little part to play in its distribution. However, as with other types of crime, there are good reasons, articulated below, to expect the distribution of incidents of OSV to be influenced by the configuration of the street network. The research reported here thus extends criminological understanding of the influence of urban form on crime risk and does so using a method imported from another discipline.

The paper is organized as follows: in the next section we discuss why the street network would be expected to influence the clustering of crime from the perspective of environmental criminology. After reviewing the relevant empirical literature, we consider the related issue of how variation in land use might be expected to affect the likelihood of crime occurrence. A series of hypotheses are formulated and subsequently tested using a sample of data from one UK police force area. A brief description of the space syntax methodology, used to quantify the characteristics of the street network, is provided before presenting empirical analyses. We conclude the paper with a discussion of the findings and what they mean for criminological theory and crime prevention.

\section{Crime Pattern Theory and Offender Collective Familiarity Surfaces: How Streets Might Shape Crime Risk}

Crime pattern theory (Brantingham and Brantingham 1984, 1993) suggests that rather than actively searching for crime opportunities in locations that are unfamiliar, offenders 
commit offenses in areas that are already known to them. Like everyone else, offenders have routine activities (Cohen and Felson 1979) and, as a consequence of engaging in these, visit some places frequently (e.g., their home, places of work and recreation) and develop an awareness of them, the places that surround them, and the paths they must travel to move between them (Brantingham and Brantingham 1993). Offenders are predicted to offend at locations encapsulated by their activity spaces that furnish exploitable criminal opportunities. Some aspects of an offender's awareness space may be highly idiosyncratic. However, since the street network shapes the possible paths from one location to another, there will be particular street segments that, purely based on their position within the street network, are more accessible and thus more likely to be part of any offender's activity space (e.g., Beavon et al. 1994).

The implication of this is that, all else equal, street segments which are more accessible and/or likely to lie in people's everyday paths will be expected to be more familiar to everyone and, consequently, more likely to be frequented and targeted by offenders. Therefore, from a crime pattern theory perspective, more crime would be expected to occur on (or near to) more "central" (to use the terminology of graph theory) street segments. Considering different types of crime, this should apply to both spontaneous and predatory violence. To explain, many predatory offenders (e.g., stranger rapists) are likely to choose a crime location in advance, based on factors such as typical levels of formal and informal surveillance, likely escape routes, and so on-factors that would influence their perceived risk of apprehension. Such an assessment, however, would not be possible for locations they do not frequent or are unfamiliar with. For such streets there would be greater uncertainty about the risks involved which-according to crime pattern theory-would reduce the likelihood that such locations would be selected, or even considered (Brantingham and Brantingham 1993; Cornish and Clarke 1986). In contrast, spontaneous or unplanned violence, by definition, relates to a crime location that is not chosen a priori. However, also implied in the term is that the crime occurs while the offender is engaged in everyday non-criminal routine activities (e.g., walking home after having gone out for a drink), in places that are typically familiar to the offender. Familiarity in this case is assumed because individuals have been shown to spend most of their time in or around just a few locations, regardless of the total number of locations they visit or the distances they typically travel (Song et al. 2010). Therefore, according to crime pattern theory, one would expect both predatory (planned) and spontaneous (unplanned) violence to occur in places the offender is familiar with.

Most studies that have examined the influence of the street network on the spatial distribution of crime at a micro level have focused either on residential burglary (e.g., Armitage 2004, 2006, 2007; Armitage and Smithson 2007; Bevis and Nutter 1977; Brantingham and Brantingham 1984; Chang 2011; Hillier 1988; Johnson and Bowers 2010; Reis and Rosa 2012; Shu 2000, 2009; Shu and Huang 2003; Ward et al. 2014; White 1990; Yang 2006; Young 1999; Young et al. 2003; Zaki and Abdullah 2012), or a combination of residential burglary and other forms of property crime such as willful damage (e.g., Beavon et al. 1994), vehicle crime (e.g., Hillier and Shu 2000; López and van Nes 2007; van Nes and López 2010), and theft (Lee et al. 2007). Some authors have included violent crime in the data analyzed, but with a few exceptions (see below) failed to disaggregate by crime type (e.g., Armitage et al. 2011; Dhiman 2006; Fanek 1997; Greenberg and Rohe 1984; Jones and Fanek 1997; Long and Baran 2006; Nubani and Wineman 2005). In general, at least in the case of residential burglary, the evidence suggests that crime is more likely to occur on more accessible street segments. However, residential burglary is a crime of stealth with rather different precipitators to OSV offenses, and so 
notwithstanding the above discussion, patterns for the two types of crime might plausibly differ.

In terms of how the configuration of the street network might influence the spatial distribution of OSV, what we currently know comes from a small number of studies that have employed the space syntax methodology. In the main, space syntax studies of violent crime have focused on street robbery. Such studies are of clear relevance to the current research, but the outcomes of such offenses will (by definition) be less serious than those considered in the current study. These studies are reviewed below but, before doing so, we provide a brief introduction to the space syntax methodology-used to quantify the characteristics of the street network-for those unfamiliar with the approach (a more detailed exposition of the full procedures of space syntax is beyond the scope of this paper; interested readers are referred to Bafna 2003, Hillier 2007, Hillier and Hanson 1984, and Summers and Johnson 2015).

\section{Space Syntax}

The overall aim of the space syntax methodology is to estimate how urban movement varies across the street network for both pedestrian and vehicular journeys. It employs techniques based on the mathematical field of graph theory, which involve an analysis of the street network, to generate a series of street network accessibility and usage measures at the street segment level. The most commonly used space syntax measure is integration, which measures accessibility or mathematical closeness centrality to estimate (pedestrian or vehicular) to-movement or destination potential. The integration value of a street segment is based on the mean depth or topological distance (the number of street segments that must be traveled) to all other segments in the network. Integration is calculated using shortest path algorithms and is adjusted for factors such as the size and shape of the network. It estimates how likely particular street segments are to be the destination for those using the network, based on the position of a street segment in the network. A second frequently reported accessibility measure is connectivity, which represents the number of street segments a given segment intersects. This is analogous to the order of a vertex in graph theory and it is this metric that has most commonly been used in studies of environmental criminology (e.g., Beavon et al. 1994; Johnson and Bowers 2010). Finally, choice is a measure of through-movement potential or mathematical betweenness centrality. This is derived by identifying the shortest paths for all possible origin-destination pairs in the network, and then counting how frequently each street segment features in these. While there is only one possible connectivity value for a given street segment, integration and choice may be calculated at varying radii (which determine which origindestination pairs are considered in the analysis), to approximate movement at different scales (e.g., to reflect pedestrian vs. vehicular movement). Both integration and choice have been shown to be highly correlated with pedestrian and vehicular flows (e.g., Hillier and Iida 2005).

The space syntax methodology differs from the graph theoretical metrics on which it is based in that it accounts for what is known about human wayfinding (Peponis et al. 1990). For example, when calculating the shortest paths between two locations, purely graph theoretical approaches consider only the network metric (or topological) distance between them. In contrast, drawing on the fact that when completing everyday journeys people prefer to travel along relatively linear routes, space syntax metrics penalize turns with larger angular deviations from an existing trajectory or path. Based on the same principle, the underlying street network used in studies of space syntax is represented by a graph of 
solely straight lines (visual lines derived from the existing street network), referred to as axial lines (more details below). This contrasts with other analytical approaches, which tend to employ existing road network databases where some of the street segments may be non-linear.

The main findings from space syntax studies that have examined the influence of the configuration of the street network on the spatial distribution of violent crime are as follows: first, counts of street robbery and violent crime tend to be greatest on segments with high integration and/or choice values, particularly at night (Alford 1996; Farooq 2007; Hillier and Sahbaz 2005; Sahbaz and Hillier 2007). Second, connectivity also appears to be associated with greater robbery counts but this relationship does not always appear as strong as for integration (Hillier and Sahbaz 2009; Nubani 2006; Reis et al. 2007). However, when the length of street segments (which accounts for the opportunity of offenses per unit of street length) is controlled for, inconsistent findings emerge. Some authors report a positive association between accessibility and crime (Baran et al. 2006, 2007), while others state that it is less accessible segments that are associated with greater numbers of robberies per unit of street length (Hillier and Sahbaz 2005).

Some of these inconsistencies may be attributable to the methodological and analytic approaches adopted. For instance, Baran et al. (2006, 2007) performed regression analyses and controlled for street segment length by including this as an independent variable in the model; their results were consistent with crime pattern theory and revealed integration (tomovement) to be positively associated with logged crime counts. In contrast, in their study, Hillier and Sahbaz (2005; also see Hillier and Sahbaz 2012) aggregated the street segments examined into 45 "bands" of similar length and calculated an aggregated number of robberies per street meter for each band, by adding up all crimes within the band and dividing by the total segment length. They reported a negative association between the aggregated number of robberies per street meter and the mean integration value of the band. Aggregating segments based on segment length, however, does not really control for any confounding effects that length may exert, and may also obscure relationships between features of the street network and crime at the segment level. Perhaps more importantly, the approach is problematic in that it ignores the fact that there is an explicit spatial structure to the street network. By aggregating the data as discussed, street segments are assumed to be independent units of analysis, which clearly they are not (Tobler 1970).

As noted above, much of the research concerned with how the street network might shape the spatial distribution of crime has focused on property crime, or analyses have been conducted for aggregated categories of offenses. To test the general utility of the theory, it is important to explicitly examine the patterning of offenses that might not be thought of as being the outcome of routine everyday activity, such as outdoor serious violent offenses. Given the paucity of research concerned with the configuration of the street network that has focused on incidents of OSV, and the variation in research methods employed hitherto, we examine this issue here. Based on crime pattern theory, which states that offenders are more likely to commit crime in places they are aware of, our first hypothesis is that:

$\mathbf{H}_{1}$ Street segments that facilitate movement to (as estimated by connectivity and integration) or through (choice) the network will be more likely to contain incidents of OSV, as offenders - just like anyone else-will be more likely to be familiar with such segments.

A potential shortcoming of space syntax is the extent to which its measures-which relate to the physical characteristics of places - are confounded with other characteristics of such places, particularly in relation to land use (Batty et al. 1998; Ratti 2004). In other 
words, if a significantly greater amount of crime takes place on more permeable street segments, is this simply because such segments host more (crime-attracting or -generating) land uses? Research has shown that particular land uses, such as entertainment, commercial and transport-related facilities, are related both to the spatial distribution of crime (e.g., Browning et al. 2010; Kinney et al. 2008; McCord and Ratcliffe 2009; Stucky and Ottensmann 2009; Weisburd et al. 2012, 2014) and the configuration of the street network (Hillier 1996, 2007; Peponis 2004). However, the joint influence of these two factorsland use and street network configuration-on crime has not previously been examined, raising the possibility that the conclusions of previous research might be spurious. Consequently, we examine the role of both influences here.

\section{Land Use}

While the street network influences the routes that people take from origins to destinations, it is the location of people's activity nodes that determines what these origins and destinations will be. Some activity nodes will be particular to an individual, while some will be shared by many. Several non-residential facilities have been found to be associated with the spatial distribution of violent crime (for a recent review, see Groff and Lockwood 2014). The facilities that have received most attention are those where alcohol can be purchased, for consumption either on- or off-site (e.g., Jennings et al. 2014; Pridemore and Grubesic 2013; Ratcliffe 2012; Roncek and Maier 1991). However, the spatial distribution of violent crime has also been found to be associated with commercial and recreational land uses more generally (e.g., Browning et al. 2010; Groff and McCord 2012; Kinney et al. 2008; Kurland et al. 2014), as well as the amount of commercial zoning in an area (Anderson et al. 2013).

As such facilities can both generate or attract crime (Brantingham and Brantingham 1995), they may exert an influence on the likelihood of crime occurrence that exceeds any contribution that might be associated with the influence of the street network on movement flows. Alternatively, and in the extreme, the location of commercial and recreational land uses - rather than the configuration of the street network-might largely explain movement flows. However, Hillier (2007) has suggested that it is the influence of the street network on pedestrian and vehicular movement that shapes the distribution of land uses, rather than the other way round; in his own words (Hillier 2007: 125),

"far from explaining away the relation between grid structure and movement by pointing to the shops, we have explained the location of the shops by pointing to the relation between grid and movement."

Of course, just because a segment has a high potential of containing certain land uses due to its position within the street network, this does not mean that this is necessarily realized. Therefore, to accurately measure the independent influence of the street network on spatial crime distributions, a land use measure is included in the analyses, and a second hypothesis is formulated, as follows:

$\mathbf{H}_{2}$ OSV will be more likely to occur on street segments with more commercial land uses after controlling for how accessible they are.

So far, we have considered how estimated movement flows along a particular street segment are expected to affect the level of crime on that street segment. According to crime pattern theory, individuals are thought to become familiar not only with the routes that they travel, but also those areas that are immediately adjacent to them (Brantingham 
and Brantingham 1982, 1993; also see Groff 2011). Moreover, Angel (1968) suggested that for robbery and other predatory offenses, offenders might favor a "critical intensity zone" that, while being isolated, is situated in close proximity to busy locations, thus yielding a "spillover" effect. One scenario might involve an offender identifying potential (moving) targets within a busy area and following them until they both reach a more isolated location, where the offender perceives the risk of apprehension as acceptable. This would be much more efficient than trying to identify a suitable target from an isolated spot, where the offender might also be more likely to appear conspicuous. In line with this, Wilcox (1973) found that there was an elevated risk of victimization in the alleyways behind shops and the periphery of nearby car parks half an hour after the shops had closed. For these reasons, we hypothesize that the risk of crime will not only be high on street segments with the highest estimated to- and through-movement flows, but also on those that are situated near such segments. That is:

$\mathbf{H}_{3}$ Street segments in close proximity to the connectivity core (i.e., the segments most directly connected to others), the integration core (i.e., the segments with the highest integration, indicative of high to-movement potential), or the choice core (i.e., the segments with the highest through-movement potential) of the network will be more likely to contain OSV than segments situated further away from these cores.

In the next section, we describe the data used to test the above hypotheses and explain how the space syntax metrics were calculated.

\section{Methodology}

\section{Data}

Data were analyzed for one of the 32 boroughs in Greater London, England. This particular borough was selected because Metropolitan Police Service (MPS) figures indicated that it was one of the areas most affected by serious violence. It is an outer London borough where the percentage of minority ethnic residents is considerably higher than the Greater London average, but which has largely mainstream rates of unemployment, crime and deprivation as compared to the rest of the city. Its estimated population for 2013 was just under 330,000, with a population density of about 75 residents per hectare (this is higher than the average for Greater London, which is about 55 residents per hectare). ${ }^{1}$

\section{Crime Data}

Data were available for crimes recorded by the MPS over the 5-year period 1 April 2002 to 31 March 2007. The offenses considered consisted of all outdoor murders, attempted murders and other forms of violence where the injuries inflicted on the victim(s) were severe. In the first instance, only homicides and attempted murders were considered, as the analyses presented here formed part of a larger research project focusing on the situational determinants of homicide and attempted murder in Greater London. The use of space syntax called for a smaller geographical area but this resulted in a crime count that was too small for meaningful analysis (i.e., 20 murders and 10 attempted murders). For this reason, the sample was expanded to also include other violent incidents where the injuries to the

\footnotetext{
${ }^{1}$ Source: http://data.london.gov.uk.
} 
Table 1 Outdoor serious violence offenses recorded by the London Metropolitan Police in the research area between April 2002 and March 2007, by crime and location type

\begin{tabular}{lccllr}
\hline & $\begin{array}{l}\text { Public } \\
\text { pathway }\end{array}$ & $\begin{array}{l}\text { Park/Green open } \\
\text { area }\end{array}$ & $\begin{array}{l}\text { Open-access car } \\
\text { park }\end{array}$ & $\begin{array}{l}\text { Other open } \\
\text { space }\end{array}$ & Total \\
\hline $\begin{array}{l}\text { Murder } \\
\begin{array}{c}\text { Attempted } \\
\text { murder }\end{array}\end{array}$ & 19 & & 1 & & 20 \\
$\begin{array}{l}\text { Aggravated } \\
\text { assault }\end{array}$ & 9 & 1 & & & 10 \\
$\begin{array}{l}\text { Robbery } \\
\text { Sexual assault }\end{array}$ & 800 & 9 & 6 & & 315 \\
Total & 7 & 3 & & 1 & 91 \\
\hline
\end{tabular}

victim(s) were classified as severe, which is the second most serious category on a fivepoint scale used by London's MPS (ranging from lethal to no injury). In this way, this research was concerned with lethal and near-lethal violent crime.

Other authors have advocated for the inclusion of incidents of this type when studying homicide. For instance, Gottfredson and Hirschi (1990: 34) stated "the difference between homicide and assault may simply be the intervention of a bystander, the accuracy of a gun, the weight of a frying pan, the speed of an ambulance or the availability of a trauma centre." In a similar way, Harries (1990: 48) argued "the legal labels 'homicide' and 'assault' represent essentially similar behaviors differing principally in outcome rather than process."

The resulting sample consisted of a total of 512 crimes for the 5-year period for which data were available. However, $13 \%$ of these offenses had to be excluded from the analyses, as no geographical coordinates were available for them. ${ }^{2}$ This produced a final sample of 447 offenses. Each offense was assigned to the nearest street segment using a Geographical Information System (GIS; the shortest distance was measured as the perpendicular to anywhere along the line, rather than the distance to the closest vertex). $95 \%$ of offenses occurred on a public pathway (e.g., street, alleyway; see Table 1).

\section{Land Use}

To allow for the estimation of the influence of land uses at the segment level, point-level land use data were obtained from UKMap. There were approximately 390,000 land use data points within the research area, of which approximately three quarters were residential. The remaining points were recorded as belonging to one of 12 categories from the National Land Use Database (NLUD) classification system. ${ }^{3}$ A "commercial" land use

\footnotetext{
2 The 65 offenses that had to be removed were mainly aggravated assaults (51) that were recorded as having occurred either on a public pathway (37) or another type of open space (14). Also missing geographic coordinates were 12 robberies, of which 11 occurred on a public pathway (the remaining offenses occurred on another type of open space), as well as one murder and one sexual assault, both of which took place on public pathways.

${ }^{3}$ The other categories were: agriculture and fisheries; community and health services; defense; education places; manufacturing; offices; transport tracks and places; unused land, water and buildings; utility services; and wholesale distribution. At the request of a reviewer, we reran the analyses presented below with offices included in the land uses considered. As the same pattern of results emerged, we discuss these no further.
} 
super-category was created by combining land uses from the "Recreation and leisure" and "Retail distribution and servicing" categories, which amounted to $4.2 \%$ of all land uses. It was not possible to determine the exact nature of each of these land use points (e.g., grocery store, restaurant) from the available data; the "Recreation and leisure" category consists of amenity, amusement and show places, libraries, museum and galleries, as well as land and water sport places, while the "Retail distribution and servicing" category includes retail distribution places and retail centers. Although the two types of land uses are different in their nature, it was assumed that both types would increase the likelihood of people (including offenders) becoming familiar with the street segments on which they were located. To calculate the total number of commercial land uses associated with each segment, each commercial land use point was assigned to the nearest segment using a GIS (again using the perpendicular to anywhere along the segment, rather than the distance to the closest vertex). Only those land uses within $100 \mathrm{~m}$ of the nearest segment were included in the analyses (97\% of all commercial land uses; $\mathrm{N}=14,351$ ); land use points excluded under this criterion largely consisted of facilities within larger parks and sports complexes that were actually some distance away from the street network (e.g., cafes, running tracks, etc.).

\section{Calculation of Space Syntax Measures}

The starting graph was an axial (fewest) straight line map covering the whole Greater London area ( $\mathrm{N}=99,476$ axial lines), which was obtained from Space Syntax Ltd. This graph had been created using an established procedure which can be summarized as follows. First, the continuous open space of the area is delineated; this covers any space that is not occupied by buildings and thus represents all potential movement (for an example, see Fig. 1a). This space is then broken down into a set of fewest and fattest convex spaces. The axial map can then be generated by identifying "the least set of straight lines which passes through each convex space and makes all axial links" (Hillier and Hanson 1984: 92; see Fig. 1b). The last part of the definition simply indicates that every line should be connected to every other line in the network (i.e., the network is continuous).

Although axial analyses can be performed at this stage, it is common to break down the network further and create a segment map. This is done by sectioning all axial lineswhich represent lines of visibility - at the points they intersect others (see Fig. 1c). The resulting street segment map can then be converted into a graph by treating the segments as nodes and connecting those that intersect each other (see Fig. 1d). Once the street segment network graph is generated, syntactic analyses may be performed.

All street segments within the research area and a 3-km buffer around it were considered in the first instance. This buffer was applied to avoid an "edge effect" in the calculation of the integration and choice measures (for the segments in the research area) that can arise with the use of artificially imposed boundaries. The 3-km limit was chosen as the maximum radius as research suggests that this encompasses most pedestrian and routine vehicular journeys in London (e.g., Hillier and Iida 2005).

Space syntax measures were calculated using Depthmap (see Turner 2004). Following Hillier (1996, 2007, 2012), integration and choice were calculated using a radius of $800 \mathrm{~m}$ (i.e., all origin-destination journeys used to compute the space syntax metrics for pedestrian movement were equal to or less then $800 \mathrm{~m}$ ) to estimate local movement (akin to pedestrian flows), and a radius of $3 \mathrm{~km}$ to estimate global movement (akin to vehicular 


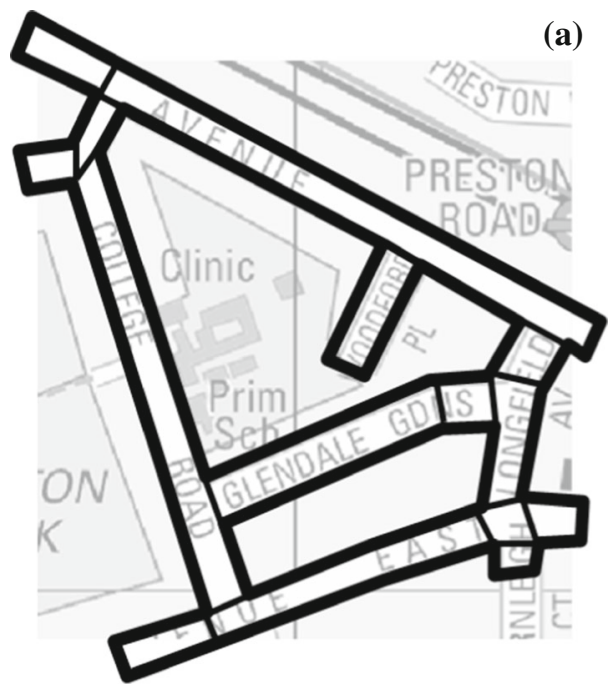

(b)

(c)
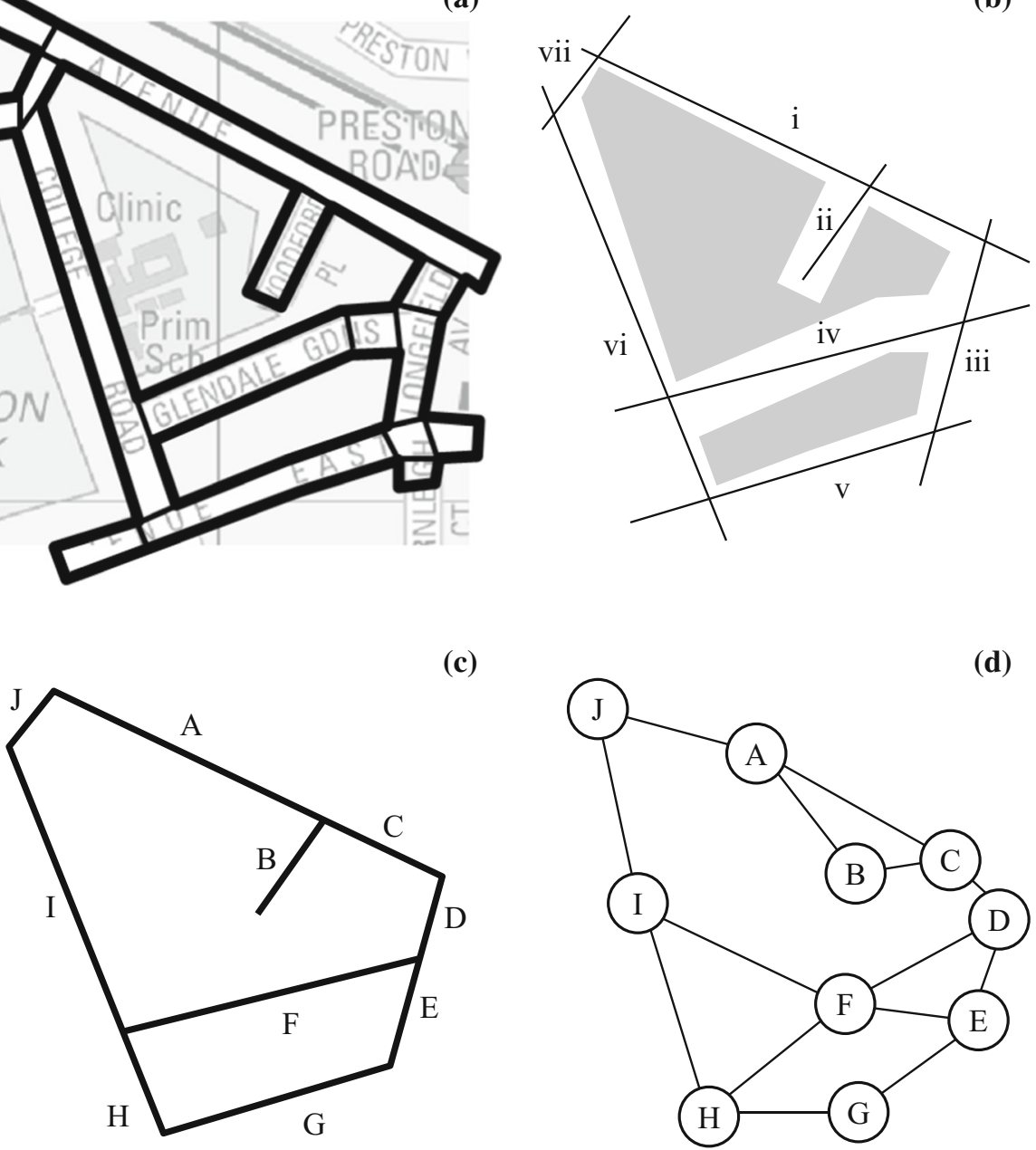

Fig. 1 Process of generating a street segment network in space syntax: a the continuous open space of the relevant area is delineated and broken down into convex spaces; $\mathbf{b}$ an axial map is created by identifying the smallest connected network of straight lines passing through such convex spaces; $\mathbf{c}$ axial lines are split at intersections to create a street segment map; and d each street segment becomes a vertex with edges representing its direct links to other vertices

flows). In line with most previous space syntax studies, a decision was made to consider both local and global measures, as they are thought to represent different levels of movement and, consequently, spatial awareness.

Shortest path algorithms were used to calculate the integration and choice measures, which can be applied using either angular deviation, metric distance, or the number of topological steps. Angular analysis - which accounts for the fact that people prefer to move in relatively straight lines-has been shown to result in more accurate estimates of movement levels when compared to the other two methods (Hillier and Iida 2005). For this reason, all space syntax measures were calculated using this method. Table 2 shows that 
Table 2 Spearman's rank correlations for the space syntax measures $(\mathrm{N}=7176$ segments $)$

N.B.: All correlations are significant at the $p<.001$ level

\begin{tabular}{llllll}
\hline & & 1 & 2 & 3 & 4 \\
\hline 1 & Connectivity & & & & \\
2 & Local integration $(\mathrm{R}=800 \mathrm{~m})$ & 0.44 & & & \\
3 & Global integration & 0.33 & 0.73 & & \\
$\quad \quad(\mathrm{R}=3000 \mathrm{~m})$ & & & & \\
4 & Local choice $(\mathrm{R}=800 \mathrm{~m})$ & 0.48 & 0.72 & 0.51 & \\
5 & Global choice $(\mathrm{R}=3000 \mathrm{~m})$ & 0.46 & 0.65 & 0.60 & 0.89 \\
\hline
\end{tabular}

while the space syntax measures are correlated, they clearly measure different things. In particular, the correlations between the connectivity and other space syntax metrics are quite modest.

To determine if any effects of accessibility on OSV extended to nearby segments, the integration, choice and connectivity cores of the network were identified. In line with previous research (Hillier 2007; Hillier et al. 1993), the integration and choice cores of the street network were identified by selecting the highest scoring $10 \%$ of all segments. Segments within $100 \mathrm{~m}$ of these cores were selected as being "nearby" to these cores of the network. ${ }^{4}$ In the case of the "connectivity core," street segments with a connectivity value of six or higher ( $\mathrm{N}=730$, or $10.2 \%$ of all segments) were classified as belonging to the connectivity core.

All 27,549 street segments (located in the research area and the 3-km buffer) were considered when calculating the space syntax measures, but only those street segments within the research area $(\mathrm{N}=7176)$ were included in the statistical analyses. To control for the fact that longer segments are likely to contain more origin and destination points, segment length was included in all analyses that follow.

\section{Results}

Most segments in the research area $(\mathrm{N}=6806$, or $95 \%$ of all segments) contained no crime. This was to be expected considering the large number of segments and the volume of offenses available for analysis. Having said this, a small number of segments contained more than one offense, up to a maximum of five crimes per segment, indicating some degree of spatial concentration (see Table 3). As expected, segments containing no crime ( $\mathrm{N}=6806$; hereafter zero-crime segments) were significantly shorter than those where at least one crime occurred $(\mathrm{N}=370$; hereafter crime-targeted segments; mean lengths 73.2 and $132.8 \mathrm{~m}$, median 56.5 and $116.4 \mathrm{~m}$, standard deviation 71.3 and $85.7 \mathrm{~m}$, respectively; Mann-Whitney test results $\mathrm{U}=1,849,321, \mathrm{Z}=15.21, p<.001)$.

\section{Analytic Strategy}

A series of regression analyses were conducted to estimate the relative influence of the space syntax measures on crime occurrence. As most segments contained no crime, we

\footnotetext{
4 This was achieved using the Select by Location tool in ArcMap, with the "within a distance of" option. This created a buffer of the size specified (in this case, 100 meters) around each segment in the core for each space syntax measure and selected any segments that intersected these buffers. The segments that were part of the actual core were then excluded from this subset.
} 
Table 3 Number of street segments in the research area by the number of incidents of outdoor serious violence offenses (between April 2002 and March 2007) they contained

\begin{tabular}{lllllll}
\hline & \multicolumn{9}{l}{ Number of offenses per segment } \\
\cline { 2 - 7 } & 0 & 1 & 2 & 3 & 4 & 5 \\
\hline Number of segments & 6806 & 311 & 45 & 11 & 2 & 1 \\
$\begin{array}{l}\text { Percentage of segments } \\
\text { Total }\end{array}$ & 94.8 & 4.3 & 0.6 & 0.2 & $<0.1$ & $<0.1$ \\
\hline
\end{tabular}

employed zero-inflated negative binomial models, with the street segment as the unit of analysis. Zero-inflated regression models (Greene 1994; Lambert 1992) provide a means to deal with overdispersion and the existence of excessive zeros. In our case, zero-inflated negative binomial models were employed-as opposed to zero-inflated Poisson modelsbecause the variance of our dependent variable (i.e., the number of crimes occurring on street segments; 0.086) was greater than the mean (0.062). Post-estimation tests also confirmed that the models selected provided the best fit to the data.

In the first instance, a series of models were performed, each assessing the influence of a single space syntax measure. After doing this, a full regression model including all space syntax measures was conducted, so that the relative influence of such measures could be determined.

The data analyzed have an explicit spatial structure and it is important to account for any effect this may have that is separate from the network structure already specified in the models. Failing to do so would potentially violate the assumption of independence common to most statistical tests. In the current case this is important because statistical models usually omit some variables that might explain observed patterns, and some of these variables may exhibit a spatial pattern such that locations that are near to each other will be more likely to share similar characteristics on important factors than those that are far apart. A number of approaches can be taken to estimate the influence of unobserved variables that vary spatially in statistical models. Here, we use a spatial lag (see Anselin and Bera 1998) calculated for the dependent variable as follows:

$$
\operatorname{SLag}_{i}=\sum_{j=1}^{N} \frac{c_{j}}{d_{i j}}
$$

where $i$ represents the segment for which the spatial lag value is being calculated; $j$ represents all other segments; $N$ is the total number of segments; $c_{j}$ is the number of crimes on segment $j$; and $d_{i j}$ is the distance (in meters) between the centroids of segments $i$ and $j^{5}$

\section{Assessing the Influence of Single Space Syntax Measures}

For all zero-inflated negative binomial models reported here and in the next section, the unit of analysis was the street segment (with $\mathrm{N}=7176$ ) and the dependent variable was

\footnotetext{
5 All street segments were included in the calculations, regardless of the distance between them and the focal street segment $i$. However, given the inverse distance weighting, those located a long distance away contribute much less than those nearby. After the analyses were completed, all models were recomputed using a spatial lag term for which the distance terms (in the denominator) were squared. The results observed were consistent with those reported here.
} 
Table 4 Standardized incidence rate ratios (sIRR) and odds ratios (sOR) of the baseline zero-inflated negative binomial model with segment length as exposure variable $(\mathrm{N}=7176)$

\begin{tabular}{lcc}
\hline Variable & $\begin{array}{l}\text { SIRR } \\
\text { Count }\end{array}$ & $\begin{array}{c}\text { sOR } \\
\text { Binary }\end{array}$ \\
\hline Control variables & & \\
Spatial lag & $1.30^{* * * *}$ & $0.34^{* * * *}$ \\
Number of commercial land uses & $1.12^{* * *}$ & $0.27^{* * *}$ \\
Likelihood ratio $\chi^{2}$ & & $31.81^{* * *}$ \\
Pseudo $\rho^{2}$ & & 0.16 \\
\hline
\end{tabular}

N.B.: $* p<.05 ; * * p<.01 ; * * * p<.001$. Constant term parameters have been omitted from this display. Likelihood ratio test that alpha $=0$ favored the negative binominal over a Poisson model was statistically significant $\left(\chi^{2}=8.63, p<.01\right)$. Vuong test favored the zero-inflated negative binomial over a standard negative binomial model $(\mathrm{Z}=3.60, p<.001)$

the number of crimes on the segment. Unless otherwise stated, diagnostic tests indicated no evidence of multicollinearity in the analyses that follow. Prior to examining the influence of the street network on crime, a "baseline" model that included only two predictors - the spatial lag variable and the number of commercial land uses in the segment-was estimated (see Table 4). While not included as a predictor variable, street segment length was included in the model as an exposure variable to account for the fact that (more) crime would be more likely on longer street segments. The estimated model yielded a statistically significant McFadden pseudo- $\rho^{2}$ value of 0.160 . Zero-inflated models have two components (for a discussion, see McDowell 2003). The first is used to estimate the probability of excess or structural zeros and is often estimated using a logistic regression (hereafter, the binary component). The second is used to estimate the likelihood of non-excess (or sampling) zeros and non-zero counts, and is typically estimated using a Poisson or-as is the case here-a negative binomial model (hereafter, the count component). Both independent variables had statistically significant coefficients indicative of a positive association with crime. This was true for both the binary and count components of the model. Considering the values themselves, an increase of one commercial unit was associated with an additional 0.014 crimes per unit of street length (the unstandardized coefficient was 0.0142 in the count part of the model) and a $15.4 \%$ reduction in the odds of a segment being "immune" from crime (the unstandardized odds ratio from the binary part of the model was 0.846).

In the case of the spatial lag variable, crime was more likely on street segments that were closer to other street segments on which (more) crimes occurred. Considering this variable in a little more detail, the spatial lag of a given street segment is influenced both by the number of crimes on other segments as well as how far away these segments are. In this way, a unit increase in the spatial lag variable may result either from, say, an additional 70 crimes on a segment that is $70 \mathrm{~m}$ away (the typical distance between adjacent street segments in 100-m blocks), or an additional 700 crimes in a segment that is $700 \mathrm{~m}$ away (because the spatial lag calculation involves dividing the total number of crimes on a segment by the distance that separates it for the segment for which the spatial lag is being calculated). Put differently, an additional single crime in an adjacent street segment (assuming this was $70 \mathrm{~m}$ away) would be associated with an increase of 0.014 in the spatial lag value (i.e., 1 divided by 70). According to the model estimates, a unit increase in the spatial lag variable was associated with a 0.0033 increase in the crime count per unit of 
street length ( 0.0033 was the unstandardized coefficient for the spatial lag variable in the count component of the model) and a decrease of $1.4 \%$ in the odds of a segment being "immune" to crime (the unstandardized odds ratio from the binary part of the model was 0.986). Based on this, an additional crime on an adjacent street segment $70 \mathrm{~m}$ away would be associated with (an increase of 0.014 in the spatial lag variable and) a decrease of $0.02 \%$ in the odds of a segment being "immune" to crime, and an additional 0.00005 crimes per unit of street length. Table 4 shows the parameter estimates as standardized coefficients to allow the relative contributions of the two variables to be more easily compared.

Table 5 shows the results from the five separate models conducted to examine the influence of each of the space syntax variables independently (see Table 5). For the index of connectivity, neither the incidence rate ratio (IRR) for the count part of the model, or the odds ratio $(\mathrm{OR})$ in the binary part were statistically significant. In contrast, for the remaining four models, statistically significant effects were observed either for the predicted count of crime (for the local integration, local choice, and global choice measures), or for the odds of a street segment being "immune" from crime (for global integration). All were in line with expectation and essentially suggest that crime was more likely on street segments for which movement to or through was higher. As shown, this was the case after accounting for the influence of the control variables (the spatial lag variable and the number of commercial land uses).

As discussed, Tables 4 and 5 show standardized coefficients. In contrast to the raw IRRs and ORs, these allow the relative influence of the independent variables included in each model to be directly compared. As expected, all else equal, there was a statistically significant and positive association between the location of commercial land uses and crime occurrence. Where the space syntax measures were significantly associated with the predicted crime count, however, it seemed that the influence of these variables was greater than the effect of the commercial land uses variable (e.g., for local integration, the standardized IRR or sIRR was 1.30, while the land use variable yielded a 1.11 sIRR value in this model). However, the number of commercial land uses did appear to be a better predictor of immunity from crime in that the estimated ORs were consistently significant, and the effects stronger in every case.

Analysis of the influence of proximity to the "movement cores" of the network yielded non-significant coefficients for the space syntax variables in most cases. The exception was for local integration, where an increase in this variable was found to be associated with a decrease in the odds of the segment being immune from crime. The changes to the McFadden pseudo- $\rho^{2}$ values (as compared to the baseline model) were modest.

\section{Assessing the Relative Influence of Space Syntax Measures}

After estimating the influence of each space syntax measure one at a time, we conducted an analysis that simultaneously considered all of the independent variables to determine their relative contributions. Two of the measures (local and global integration) led to high variance inflation factor (VIF) values (i.e., $>10$ ), which are indicative of multicollinearity problems. After excluding these two variables, all VIFs were $<10$. The results of this final model are shown in Table 6.

For this model, the number of commercial land uses on a segment and the spatial lag were again statistically significant and positively related to the number of crimes. In addition, an increase in the spatial lag-but not the number of commercial land uses-was associated with a decrease in the odds of a segment being immune from crime. Having 


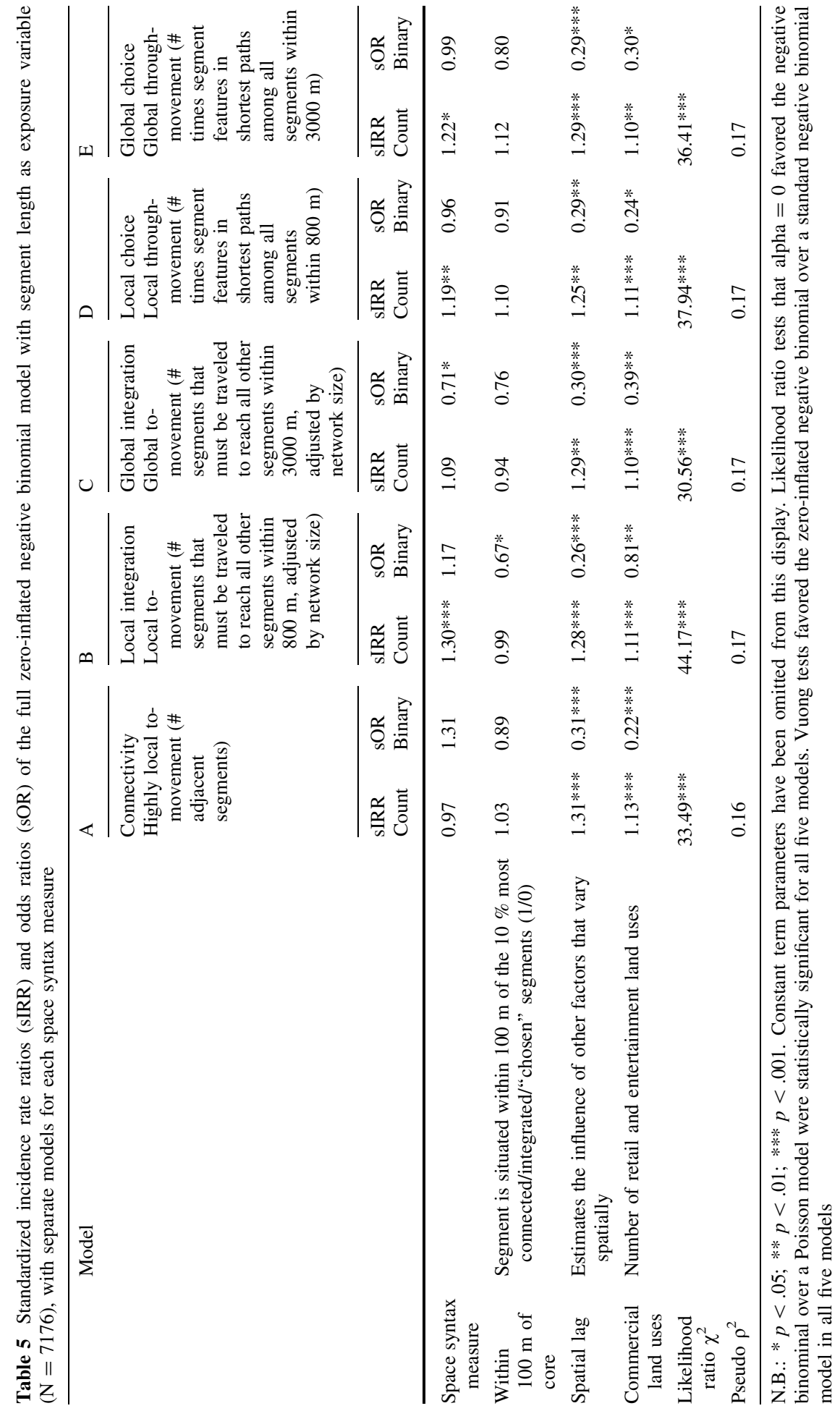


Table 6 Standardized incidence rate ratios (sIRR) and odds ratios (sOR) of the full zero-inflated negative binomial model with segment length as exposure variable $(\mathrm{N}=7176)$

\begin{tabular}{llc}
\hline Variable & $\begin{array}{l}\text { sIRR } \\
\text { Count }\end{array}$ & $\begin{array}{c}\text { sOR } \\
\text { Binary }\end{array}$ \\
\hline Accessibility & & 1.38 \\
Connectivity & $0.81^{* *}$ & 0.60 \\
Within $100 \mathrm{~m}$ of top $10 \%$ connected (1/0) & 0.96 & $0.52^{*}$ \\
Within $100 \mathrm{~m}$ of top $10 \%$ locally integrated $(1 / 0)$ & 1.02 & 0.69 \\
Within $100 \mathrm{~m}$ of top $10 \%$ globally integrated $(1 / 0)$ & 1.01 & 0.49 \\
Betweenness & & 1.37 \\
Local choice $(\mathrm{R}=800 \mathrm{~m})$ & 1.12 & 2.01 \\
Within $100 \mathrm{~m}$ of top $10 \%$ locally "chosen" (1/0) & 1.10 & 1.58 \\
Global choice $(\mathrm{R}=3000 \mathrm{~m})$ & $1.28^{* *}$ & $0.09^{*}$ \\
Within $100 \mathrm{~m}$ of top $10 \%$ globally "chosen" (1/0) & $1.20^{*}$ & 0.07 \\
Control variables & & $49.32^{* *}$ \\
Spatial lag & $1.32^{* *}$ & 0.18 \\
Number of commercial land uses & $1.13^{* * *}$ \\
Likelihood ratio $\chi^{2}$ & & \\
Pseudo $\rho^{2}$ & & \\
\hline
\end{tabular}

N.B.: $* p<.05 ; * * p<.01, * * * p<.001$. Constant term parameters have been omitted from this display. Likelihood ratio test that alpha $=0$ favored the negative binominal over a Poisson model was statistically significant $\left(\chi^{2}=16.28, p<.001\right)$. Vuong test favored the zero-inflated negative binomial over a standard negative binomial model $(\mathrm{Z}=4.16, p<.001)$

accounted for these influences, significant increases in the predicted crime count were also significantly associated with increases in global choice (through-movement), as predicted. Local integration (to-movement) and local choice (through-movement at a smaller scale) yielded significant coefficients in the single-measure models reported earlier, but failed to reach significance in the full model (see Fig. 2 for an illustration of how global choice relates to the spatial distribution of OSV). Also contrary to hypotheses, connectivity was significantly and negatively associated with predicted crime counts, so that an increase in connectivity was related to a decrease in crime. No space syntax measures yielded significant ORs in the binary part of the model.

The criminogenic effect of global choice appeared to extend to nearby segments. This is apparent in the statistically significant and positive sIRR for the variable that indicated proximity to those segments situated within $100 \mathrm{~m}$ of the global choice core (i.e., the $10 \%$ of segments with the highest global choice values; sIRR $=1.20, p<.05$ ). Being situated within $100 \mathrm{~m}$ of the local integration core was also found to be associated with a significant reduction of the odds of being immune from crime ( $\mathrm{sOR}=0.52, p<.05)$. None of the other core proximity variables yielded significant coefficients. The model, as presented in Table 6 , yielded a pseudo- $\rho^{2}$ value of 0.179 , which was the highest of all those tested. ${ }^{6}$

\footnotetext{
${ }^{6}$ In response to one of the reviewers' concerns, all the models were reran after including an additional predictor that indicated the number of public transport hubs (i.e., bus stops, bus stations, subway entrances, and train stations) on the segment. The findings remained unaffected, so the results from the original, more parsimonious models are reported instead.
} 


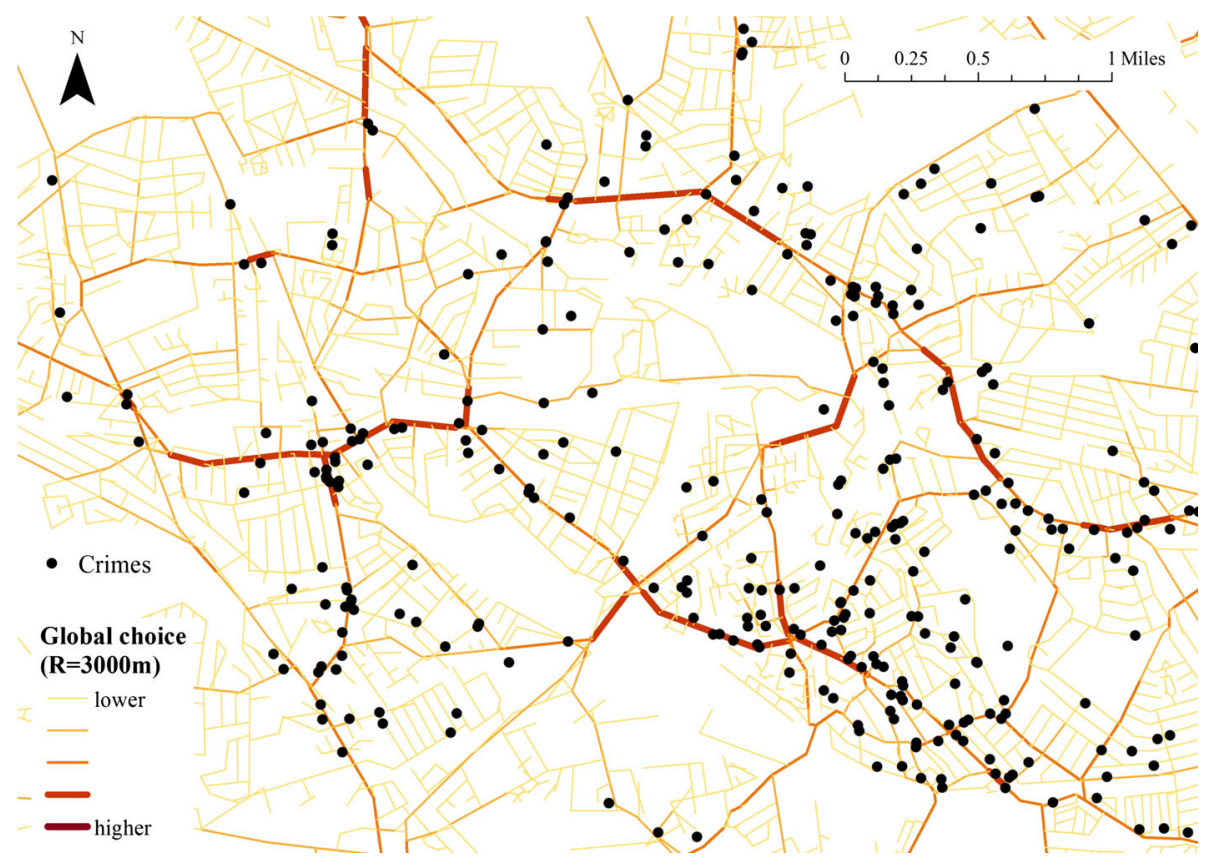

Fig. 2 Section of research area displaying the spatial distribution of crimes against street segments, colored based on the segments' global choice values. N.B.: Classification based on natural breaks

\section{Summary and Discussion}

The results presented here provide mixed support for the hypotheses formulated. When the space syntax measures were examined one at a time, as hypothesized, predicted crime counts appeared to be greater for segments that had high levels of integration (to-movement potential) and choice (through-movement potential), both at local (which approximates pedestrian movement) and global (which approximates vehicle movement) levels. In the case of connectivity, which provides the most localized estimate of to-movement, the estimated coefficients were non-significant but, if anything, and in contrast to expectation, suggested that crime was less likely on street segments for which local to-movement would be high. In the full model, this effect was statistically significant. Due to problems of multicollinearity, it was not possible to examine the unique influence of every space syntax variable simultaneously. However, the analysis conducted indicated that at the global scale, through-movement was positively associated with crime risk and that this effect extended to nearby street segments. At the local scale, the direction of the estimated effect of through-movement was consistent with the previous analysis, but was non-significant after accounting for the influence of the other variables.

As noted, the independent contributions of local and global integration could not be evaluated in the full model (due to multicollinearity problems), so these results are harder to interpret. However, assuming the positive associations between the integration measures and crime occurrence had remained in the full model, a scenario would emerge where an increase in accessibility at the most local level — as estimated through connectivity — would be associated with a reduction in the likelihood of victimization, while an increase in 
accessibility in relation to local (pedestrian) and global (vehicular) journeys-as estimated by the integration measures-would have the opposite effect.

Why the different measures of accessibility might have opposing effects will be for future research to establish, but we offer one interpretation here. Before discussing this, it is important to consider how the different measures are constructed. The index of connectivity is calculated by counting how many other segments each street segment is directly connected to. Thus, no consideration is given to those segments to which a segment is not directly connected. This ignores the position and influence of a segment in the wider network within which it is situated. In contrast, the other measures of space syntax (i.e., integration and choice) do take account of the position of a street segment within the wider network. This difference is partly illustrated by the fact that the correlations between connectivity and the other space syntax measures were not as strong as those among the other measures (see Table 2, presented earlier).

Thus, it is possible that connectivity and the space syntax measures of integration and choice measure rather different things. Hillier and Iida (2005) have shown both integration and choice to be highly correlated with pedestrian and vehicular flows, but no such data are available relating to connectivity. One possibility is that since connectivity is not strongly correlated with the other space syntax measures, it may not represent a good estimate of the general movement of people through or to a street segment (note how differently the segments with high values of global choice and connectivity are distributed among the network, in Figs. 2 and 3, respectively). Instead, being a very local indicator of accessibility, it may represent a proxy for the ambient movement of "locals" within an areathose who perhaps have the most incentive to act as guardians against crime in their neighborhood (see Jacobs 1961; Newman 1972). In contrast, the more global estimates of integration and choice-which consider the wider network in their computation-may better identify the places which larger volumes of people (including offenders) from across the wider city will frequent and become aware of. This increase in usage and awareness may increase opportunities for crime without generating a complementary increase in active guardianship. Further research might aim to test such hypotheses.

As stated in the introduction, separate bodies of literature have considered the influence of either the street network or land use in isolation, but no previous studies have tested their joint contribution. Since one factor may mediate or even explain the role of the other, in our view one of the most important contributions of this study was the simultaneous modelling of these two aspects of urban form. Our analyses suggest that both factors have a part to play. Of particular interest is the finding that-having accounted for the distribution of commercial land uses-incidents of OSV were more likely to be found on or nearby (within $100 \mathrm{~m}$ ) to those street segments for which global through-movement was high. This is consistent with the findings of Angel (1968) and Wilcox (1973), who found the streets and alleys behind or near busy roads to be at greater risk of crime, and suggests a spillover effect of the influence of the street network on crime.

The current findings inform criminological understanding and also have implications for crime prevention. For example, one recommendation is that interventions (e.g., police patrols or CCTV cameras) intended to suppress OSV should focus not only on (more accessible and/or traveled) main streets, but also on those that are adjacent to or within close proximity of them, particularly those that contain commercial land uses.

This study was not without limitations. For instance, due to our focus being on a lowincidence crime type, the small sample size did not allow for disaggregation by time of the day or by day of the week. Such disaggregation would enable the differentiation of spatial awareness (the focus of this paper, which crime pattern theory is concerned with) and 


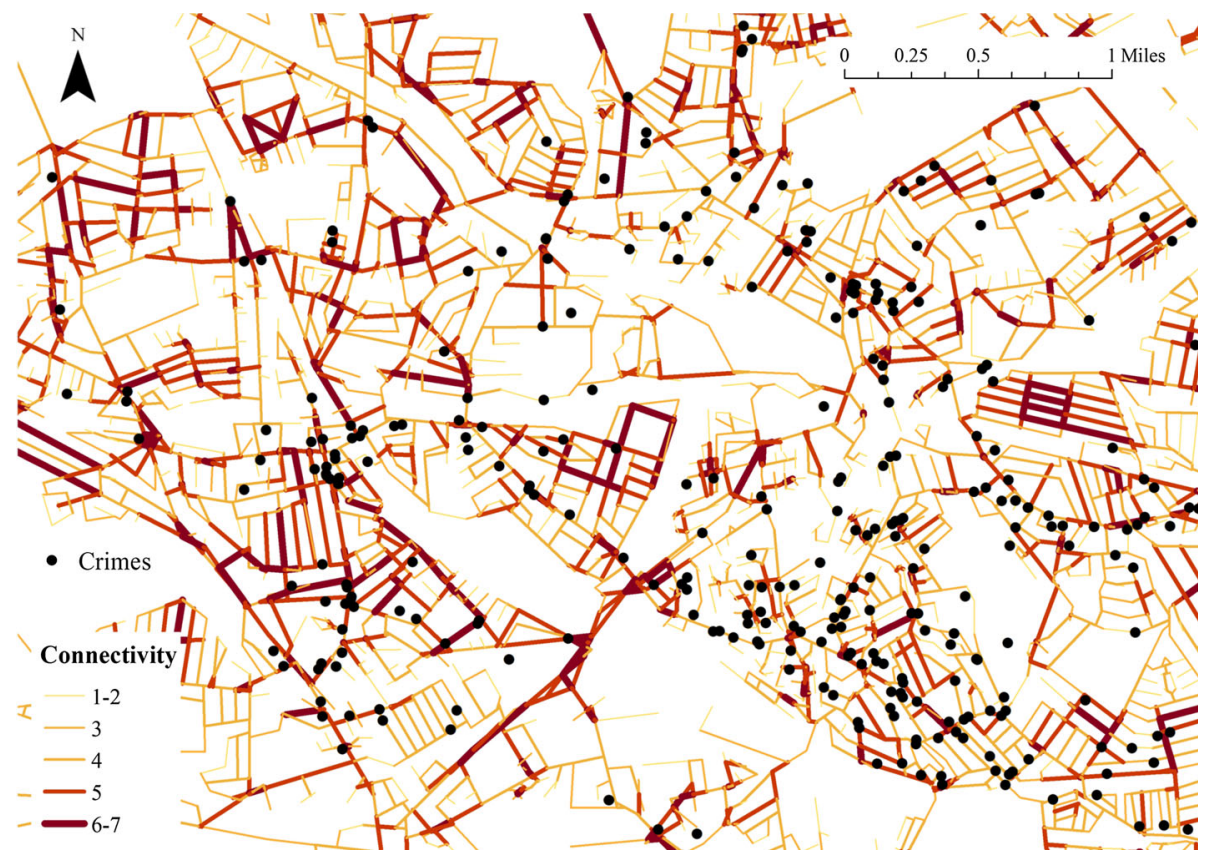

Fig. 3 Section of research area displaying the connectivity values of the street segments against the spatial distribution of crimes

space-time-specific crime opportunities, which result from the routine activities of individuals (Cohen and Felson 1979). Previous research has shown ambient population levels to vary over time, with pedestrian flows peaking at around $1 \mathrm{pm}$ and dipping at $4 \mathrm{am}$, and with weekdays tending to be busier than weekends (Aultman-Hall et al. 2009). For this reason, it is possible that the relationships observed between the configuration of the street network and crime occurrence may vary in strength (and significance) at different times of the day (see also Johnson and Bowers 2013). In the same way, movement flows driven by commercial land uses may also be time-dependent, as different businesses will be open at different times of the day. The land use data examined here was not sufficiently detailed to allow us to disaggregate on this basis, but future researchers with access to better land use data and crime data from higher-crime areas may be able to conduct such analyses.

Another limitation of the current research is that data for other variables that may influence the likelihood of crime occurrence were not available for analysis, and hence not explicitly included in the models (though we attempted to estimate their influence using a spatial lag term). For example, in a series of studies that involved the collection of rich data at the street segment level, Weisburd et al. (2012) found that factors such as ethnic heterogeneity and other indicators of social disorganization were associated with crime risk (see also Weisburd et al. 2014). These latter studies, however, did not examine the influence of the street network in the way described here, and hence future studies might aim to combine these two approaches to provide a still more complete understanding of what factors influence crime risk at the street segment level, and if and how these factors interact. 
Neighborhood-level variables and their effect on OSV might also be examined in the future, using a hierarchical modeling framework. Some authors have argued this approach better approximates the spatial decision making process of offenders, which is thought to consist of "a series of spatially nested choices" (Taylor and Gottfredson 1986: 395-396). In this way, an offender may select a neighborhood in the first instance, and then make subsequent decisions as to which street, and eventually individual target, to select. Such an approach has been adopted for the crime of burglary (Davies and Johnson 2015; Johnson and Bowers 2010) but no studies have used such an approach for other forms of crime. This was not possible in the current study as such models are difficult to specify for zero-inflated models and not available in most software packages.

As with any other study, the issue of external validity applies. It is possible that the findings reported are not applicable to other crime types, or locations. The fact that most of the results are largely consistent with previous research is encouraging, but replication will be required before the external validity of the findings can be established. To conclude, the current study suggests that, after controlling for other factors (observed and estimated), both the configuration of the street network and the spatial distribution of commercial land uses systematically influence the placement of OSV. This is an important finding since previous research has either considered only the effect of the street network or that of land use on the spatial distribution of crime, but not both within a single study. Overall, the research provides further support for theories of environmental criminology and, importantly, suggests their utility in explaining the spatial distribution of expressive as well as acquisitive crimes.

Acknowledgments Thanks are owed to Space Syntax Ltd. and UCL Bartlett School of Architecture for providing access to Depthmap software and the axial line data for the research area, and for support and advice relating to such data, in particular Professor Bill Hillier, Alasdair Campbell, Shinichi Iida, and Alain Chiaradia. We are also grateful to the Metropolitan Police for supporting this research by providing access to crime data, office space, and other assistance, especially Professor Betsy Stanko, Dr. Paul Dawson, Ann Walker and all analysts at the Strategic Research and Analysis Unit, Superintendent Dr. Jacqueline Sebire, formerly of SCD1, and Trevor Adams and Carly Mellin at the GIS Services Team.

Open Access This article is distributed under the terms of the Creative Commons Attribution 4.0 International License (http://creativecommons.org/licenses/by/4.0/), which permits unrestricted use, distribution, and reproduction in any medium, provided you give appropriate credit to the original author(s) and the source, provide a link to the Creative Commons license, and indicate if changes were made.

\section{References}

Alford V (1996) Crime and space in the inner city. Urban Des Stud 2:45-76

Anderson JM, MacDonald JM, Bluthenthal R, Ashwood JS (2013) Reducing crime by shaping the built environment with zoning: an empirical study of Los Angeles. Univ PA Law Rev 161:699-756

Angel S (1968) Discouraging crime through city planning (Working paper no. 75). University of California at Berkeley, Center for Planning and Development Research, Berkeley

Anselin L, Bera A (1998) Spatial dependence in linear regression models with an introduction to spatial econometrics. In: Ullah A, Giles D (eds) Handbook of applied economic statistics. Marcel Dekker, New York, pp 237-289

Armitage R (2004) Secured by design: an investigation of its history, development and future role in crime reduction. Unpublished doctoral thesis, University of Huddersfield

Armitage R (2006) Predicting and preventing: developing a risk assessment mechanism for residential housing. Crime Prev Community Saf 8:137-149 
Armitage R (2007) Sustainability versus safety: confusion, conflict and contradiction in designing out crime. In: Farrell G, Bowers KJ, Johnson SD, Townsley M (eds) Imagination for crime prevention: essays in honour of Ken Pease (Crime Prevention Studies 21). Criminal Justice Press, Monsey, pp 81-110

Armitage R, Smithson H (2007) Alley-gating revisited: the sustainability of residents' satisfaction? Int J Crim. http://www.internetjournalofcriminology.com/Armitage\%20Smithson\%20-\%20Alley-gating\% 20Revisited.pdf. Accessed 11 June 2016

Armitage R, Monchuk L, Rogerson M (2011) It looks good, but what is it like to live there? Exploring the impact of innovative housing design on crime. Eur J Crim Pol Res 17:29-54

Aultman-Hall L, Lane D, Lambert RR (2009) Assessing the impact of weather and season on pedestrian traffic volumes. In: Paper presented at the 88th annual meeting of the transportation research board, Washington

Bafna S (2003) Space syntax: a brief introduction to its logic and analytical techniques. Environ Behav 35:17-19

Baran PK, Smith WR, Toker U (2006) Conflict between space and crime: exploring the relationship between spatial configuration and crime location. In: Paper presented at the 37th annual conference of the Environmental Design Research Association (EDRA), Atlanta

Baran PK, Smith WR, Toker U (2007) The space syntax and crime: evidence from a suburban community. In: Kubat AS, Ertekin Ö, Güney YI, Eyüboğlu E (eds) Proceedings of the sixth international space syntax symposium. ITU Faculty of Architecture, Istanbul, pp 119-01 to 119-06

Batty M, Jiang B, Thurstain-Goodwin M (1998) Local movement: agent-based models of pedestrian flows.UCL Centre for Advanced Spatial Analysis, London

Beavon DJK, Brantingham PL, Brantingham PJ (1994) The influence of street networks on the patterning of property offenses. In: Clarke RV (ed) Crime prevention studies, vol 2. Willow Tree Press, New York, pp 115-148

Bevis C, Nutter JB (1977) Changing street layouts to reduce residential burglary. In: Paper presented at the 29th annual meeting of the American Society of Criminology, Atlanta

Brantingham PL, Brantingham PJ (1982) Mobility, notoriety, and crime: a study of crime patterns in urban nodal points. J Environ Syst 11:89-99

Brantingham PJ, Brantingham PL (1984) Patterns in crime. Macmillan, New York

Brantingham PL, Brantingham PJ (1993) Nodes, paths and edges: considerations on the complexity of crime and the physical environment. J Environ Psychol 13:3-28

Brantingham PL, Brantingham PJ (1995) Criminality of place: crime generators and crime attractors. Eur J Crim Pol Res 3:5-26

Browning CR, Byron RA, Calder CA, Krivo LJ, Kwan MP, Lee JY, Peterson RD (2010) Commercial density, residential concentration, and crime: land use patterns and violence in neighborhood context. J Res Crime Delinq 47:329-357

Chang D (2011) Social crime or spatial crime? Exploring the effects of social economical, and spatial factors on burglary rates. Environ Behav 43:26-52

Cohen LE, Felson M (1979) Social change and crime rate trends: a routine activity approach. Am Soc Rev 44:588-608

Cornish DB, Clarke RV (1986) The reasoning criminal: rational choice perspectives in offending. Springer, New York

Davies T, Johnson SD (2015) Examining the relationship between road structure and burglary risk via quantitative network analysis. J Quant Criminol 31:481-507

Dhiman D (2006) Identifying the relationship between crime and street layout using space syntax technology. Unpublished Masters dissertation, University of Cincinnati

Fanek MF (1997) The use of space syntax methodology in predicting the distribution of crime in urban environments. Unpublished doctoral thesis, Texas Tech University

Farooq A (2007) Social malice by housing type. In: Kubat AS, Ertekin Ö, Güney YI, Eyüboğlu E (eds) Proceedings of the sixth international space syntax symposium. ITU Faculty of Architecture, Istanbul, pp 024-01 to 024-24

Gottfredson MR, Hirschi T (1990) A general theory of crime. Stanford University Press, Stanford

Greenberg SW, Rohe WM (1984) Neighborhood design and crime: a test of two perspectives. J Am Plann Assoc 50:48-61

Greene WH (1994) Accounting for excess zeros and sample selection in Poisson and negative binomial regression models. In: Working paper EC-94-10. Leonard N. Stern School of Business, New York University

Groff ER (2011) Exploring 'near': characterizing the spatial extent of drinking place influence on crime. Aust N Z J Criminol 44:156-179 
Groff ER, Lockwood B (2014) Criminogenic facilities and crime across street segments in Philadelphia: uncovering evidence about the spatial extent of facility influence. J Res Crime Delinq 51:277-314

Groff E, McCord ES (2012) The role of neighborhood parks as crime generators. Secur J 25:1-24

Harries KD (1990) Serious violence: patterns of homicide and assault in America. Thomas, Springfield

Hillier B (1988) Against enclosure. In: Teymour N, Markus T, Wooley T (eds) Rehumanising housing. Butterworths, London, pp 63-88

Hillier B (1996) Cities as movement economies. Urban Des Int 1:49-60

Hillier B (2007) Space is the machine, e-ed. Cambridge University Press, Cambridge

Hillier B (2012) Studying cities to learn about minds: some possible implications of space syntax for spatial cognition. Environ Plann B 39:12-32

Hillier B, Hanson J (1984) The social logic of space. Cambridge University Press, Cambridge

Hillier B, Iida S (2005) Network and psychological effects in urban movement. In: Cohn AG, Mark DM (eds) Proceedings of spatial information theory: international conference, COSIT 2005, Ellicottsville, 14-18 Sept 2005. Springer, Berlin, pp 475-490

Hillier B, Sahbaz O (2005) High resolution analysis of crime patterns in urban street networks: an initial statistical sketch from an ongoing study of a London borough. In: van Nes A (ed) Proceedings of the fifth international space syntax symposium. University of Technology, Delft, pp 451-478

Hillier B, Sahbaz O (2009) An evidence based approach to crime and urban design. In: Cooper R, Boyko C, Evans G, Adams M (eds) Designing sustainable cities: decision-making tools and resources for design. Routledge, London, pp 163-186

Hillier B, Sahbaz O (2012) Safety in numbers: high-resolution analysis of crime in street networks. In: Ceccato V (ed) The urban fabric of crime and fear. Springer, London, pp 111-137

Hillier B, Shu SCF (2000) Crime and urban layout: the need for evidence. In: MacLaren V, Ballintyne S, Pease K (eds) Secure foundations: key issues in crime prevention, crime reduction and community safety. IPPR, London, pp 224-248

Hillier B, Penn A, Hanson J, Grajewski T, Xu J (1993) Natural movement or configuration and attraction in urban pedestrian movement. Environ Plann B 20:29-66

Jacobs J (1961) The death and life of great American cities. Random House, New York

Jennings JM, Milam AJ, Greiner A, Furr-Holden CDM, Curriero FC, Thornton RJ (2014) Neighborhood alcohol outlets and the association with violent crime in one Mid-Atlantic city: the implications for zoning policy. J Urban Health 91:62-71

Johnson SD, Bowers KJ (2010) Permeability and burglary risk: are cul-de-sacs safer? J Quant Criminol 26:89-111

Johnson SD, Bowers KJ (2013) How guardianship dynamics may vary across the street network: a case study of residential burglary. In: Ruiter S, Bernasco W, Huisman W, Bruinsma G (eds) Eenvoud \& Verscheidenheid: liber amicorumvoor Henk Elffers. Wrije Universiteit Amsterdam, Amsterdam, pp 305-318

Jones M, Fanek MF (1997) Crime in the urban environment. In: Hillier B (ed) Proceedings of the first international space syntax symposium. University College London, London, pp 25.1-25.11

Kinney JB, Brantingham PL, Wuschke K, Kirk MG, Brantingham PJ (2008) Crime attractors, generators and detractors: land use and urban crime opportunities. Built Environ 34:62-74

Kurland J, Tilley N, Johnson SD (2014) The football 'hotspot' matrix. In: Hopkins M, Treadwell J (eds) Football hooliganism, fan behaviour and crime: contemporary issues. Palgrave, New York, pp 21-48

Lambert D (1992) Zero-inflated Poisson regression, with an application to defects in manufacturing. Technometrics 34:1-14

Lee Y, Choi J, Park Y-S, Kang B, Choi H-C (2007) The CCTV system as a tool toward achieving CPTED in a residential area of Bucheon, Korea. In: High Commission for the Development of Arriyadh (ed) Proceedings of housing symposium 3. High Commission for the Development of Arriyadh, Arriyadh, pp 225-237

Long Y, Baran PK (2006) Spatial configuration and actual crime locations in a university campus setting. In: Paper presented at the 37th annual conference of the Environmental Design Research Association, Atlanta

López MJJ, van Nes A (2007) Space and crime in Dutch built environments: macro and micro scale spatial conditions for residential burglaries and thefts from cars. In: Kubat AS, Ertekin Ö, Güney YI, Eyüboğlu E (eds) Proceedings of the sixth international space syntax symposium. ITU Faculty of Architecture, Istanbul, pp 026-01 to 026-14

McCord ES, Ratcliffe JH (2009) Intensity value analysis and the criminogenic effects of land use features on local crime patterns. Crime Patterns Anal 2:17-30

McDowell A (2003) From the help desk: hurdle models. Stata J 3:178-184

Newman O (1972) Defensible space: crime prevention through urban design. Macmillan, New York 
Nubani L (2006) Targets for crime: measuring the spatial and visual attributes of crime locations using space syntax. Unpublished doctoral thesis, University of Michigan

Nubani L, Wineman J (2005) The role of space syntax in identifying the relationship between space and crime. In: van Nes A (ed) Proceedings of the fifth international space syntax symposium. University of Technology, Delft, pp 413-422

Peponis J (2004) Space Syntax. Implications 4(12):1-4

Peponis J, Zimring C, Choi YK (1990) Finding the building in wayfinding. Environ Behav 22:555-590

Pridemore WA, Grubesic TH (2013) Alcohol outlets and community levels of interpersonal violence: spatial density, outlet type, and seriousness of assault. J Res Crime Delinq 50:132-159

Ratcliffe JH (2012) The spatial extent of criminogenic places: a changepoint regression of violence around bars. Geogr Anal 44:302-320

Ratti C (2004) Urban texture and space syntax: some inconsistencies. Environ Plann B 31:487-499

Reis AT, Rosa CG (2012) Configuration, land use, perception, and security: an analysis of residential burglary. In: Greene M, Reyes J, Castro A (eds) Proceedings of the eighth international space syntax symposium. PUC, Santiago, pp 8130:1-8130:14

Reis AT, Vedana L, Dittmar C (2007) An analysis of street robbery and residential burglary through integration of axial lines, segments connectivity and GIS. In: Kubat AS, Ertekin Ö, Güney YI, Eyüboğlu E (eds) Proceedings of the sixth international space syntax symposium. ITU Faculty of Architecture, Istanbul, pp 025-01 to 025-12

Roncek DW, Maier PA (1991) Bars, blocks, and crimes revisited: linking the theory of routine activities to the empiricism of 'hot spots'. Criminology 29:725-753

Sahbaz O, Hillier B (2007) The story of the crime: Functional, temporal and spatial tendencies in street robbery. In: Kubat AS, Ertekin Ö, Güney YI, Eyüboğlu E (eds) Proceedings of the sixth international space syntax symposium. ITU Faculty of Architecture, Istanbul, pp 022-01 to 022-14

Shu SCF (2000) Housing layout and crime vulnerability. Urban Des Int 5:177-188

Shu SCF (2009) Spatial configuration of residential area and vulnerability of burglary: Case studies from UK and Taiwan. In: Koch D, Marcus L, Steen J (eds) Proceedings of the seventh international space syntax symposium. KTH, Stockholm, pp 102:1-102:15

Shu SCF, Huang JNH (2003) Spatial configuration and vulnerability of residential burglary: a case study of a city in Taiwan. In: Hanson J (ed) Proceedings of the fourth international space syntax symposium. University College London, London, pp 46.1-46.14

Song C, Qu Z, Blumm N, Barabási AL (2010) Limits of predictability in human mobility. Science 327:1018-1021

Stucky TD, Ottensmann JR (2009) Land use and violent crime. Criminology 47:1223-1264

Summers L, Johnson SD (2015) Using space syntax to inform crime prevention. In: Bichler G, Malm A (eds) Disrupting criminal networks: network analysis in crime prevention. Lynne Rienner, Boulder

Taylor RB, Gottfredson S (1986) Environmental design, crime, and prevention: an examination of community dynamics. Crime Justice 8:387-416

Tobler WR (1970) A computer movie simulating urban growth in the Detroit region. Econ Geogr 46:234-240

Turner A (2004) Depthmap 4: a researcher's handbook. Bartlett school of graduate studies. University College London, London

van Nes A, López MJJ (2010) Macro and micro scale spatial variables and the distribution of residential burglaries and theft from cars. J Space Syntax 1:296-314

Ward JT, Nobles MR, Youstin TJ, Cook CL (2014) Placing the neighborhood accessibility-burglary link in social-cultural context. Crime Delinq 60:739-763

Weisburd DL, Groff ER, Yang SM (2012) The criminology of place: street segments and our understanding of the crime problem. Oxford University Press, Oxford

Weisburd D, Groff ER, Yang S-M (2014) Understanding and con-trolling hot spots of crime: the importance of formal and informal social controls. Prev Sci 15:31-43

White GF (1990) Neighborhood permeability and burglary rates. Justice Q 7:57-67

Wilcox S (1973) The prevention and control of robbery (volume three: the geography of robbery). Center on Administration of Criminal Justice, University of California at Davis, Davis

Yang X (2006) Exploring the influence of environmental features on residential burglary using spatialtemporal pattern analysis. Unpublished doctoral thesis, University of Florida

Young C (1999) The Smithdown Road pilot 'alleygating' project. Unpublished report submitted to the Safer Merseyside Partnership. University of Liverpool, Department of Civic Design report 
Young C, Hirschfield A, Bowers KJ, Johnson SD (2003) Evaluating situational crime prevention: The Merseyside 'alleygating' schemes. In: Kidner DB, Higgs G, White S (eds) Socio-economic applications of geographic information science (Innovations in GIS, vol 9). Taylor and Francis, London, pp 37-50

Zaki SA, Abdullah J (2012) Layout design and its effects on burglary. Proc - Soc Behav Sci 42:329-339 